\title{
Cancer Stem Cells in Brain Tumor Biology
}

\author{
J.N. RICH* AND C.E. EYLER*广 \\ *Department of Stem Cell Biology and Regenerative Medicine, Cleveland Clinic, Cleveland, \\ Ohio 44195; 'Department of Pharmacology and Cancer Biology and Medical Scientists Training Program, \\ Duke University, Durham, North Carolina 27710
}

\begin{abstract}
Tumors are aberrant organ systems containing a complex interplay between the neoplastic compartment and recruited vascular, inflammatory, and stromal elements. Furthermore, most cancers display a hierarchy of differentiation states within the tumor cell population. Molecular signals that drive tumor formation and maintenance commonly overlap with those involved in normal development and wound responses - two processes in which normal stem cells function. It is therefore not surprising that cancers invoke stem cell programs that promote tumor malignancy. Stem-cell-like cancer cells (or cancer stem cells) need not be derived from normal stem cells but may be subjected to evolutionary pressures that select for the capacity to self-renew extensively or differentiate depending on conditions. Current cancer model systems may not fully recapitulate the cellular complexity of cancers, perhaps partially explaining the lack of power of these models in predicting clinical outcomes. New methods are enabling researchers to identify and characterize cancer stem cells. Our laboratory focuses on the roles of brain tumor stem cells in clinically relevant tumor biology, including therapeutic resistance, angiogenesis, and invasion/metastasis. We hope that these studies will translate into improved diagnostic, prognostic, and therapeutic approaches for these lethal cancers.
\end{abstract}

Primary brain tumors comprise a large family of cancers ( $>160$ types according to the World Health Organization [WHO]) (Furnari et al. 2007). The most common primary intrinsic brain tumors are gliomas in adults and medulloblastomas in children. Gliomas are defined by their morphologic and marker similarities to the glia (supporting cells of the brain), which include astrocytes and oligodendrocytes, and they are named astrocytomas or oligodendrogliomas (note that ependymomas may be included as glial tumors, but they display very different biological behavior and thus are commonly considered separately). Gliomas are graded by histologic criteria that include the presence of mitoses, aberrant nuclear or cytoplasmic morphology, glomeruloid angiogenesis, and necrosis, according to a WHO system of grading from I to IV, with grades increasing with more severe malignancy. Grade III gliomas (anaplastic astrocytoma or anaplastic astrocyoma) and grade IV gliomas (glioblastoma multiforme) are the most common and lethal of the gliomas and are treated in a similar manner. Standard of care for malignant gliomas (grade III and IV gliomas) consists of maximal surgical resection, followed by external beam radiation with concurrent chemotherapy (the oral methylator temozolomide), and then adjuvant temozolomide chemotherapy (Stupp et al. 2005). Unfortunately, tumor recurrence is essentially universal and no therapies have clear benefit in improving the survival of patients experiencing tumor recurrence or progression. The median survival for glioblastoma patients remains to be only 15 months. The outcome for children diagnosed with medulloblastoma is relatively better than for adults with glioblastoma but even long-term survivors commonly suffer long-term disability, including decreased intelligence. In fact, since the recent improvements in treating childhood leukemias, brain tumors are now the most common cause of pediatric cancer deaths. Thus, brain tumors present a severe clinical challenge, and the overall survival rate of patients has changed little in 30 years.
This chapter serves to highlight the work of the Rich laboratory within the context of this field. Because a number of laboratories share a similar research focus, this discussion represents only a small fraction of the ongoing work in the field and contains opinions of the author that may differ from those of other researchers.

\section{CANCER STEM CELLS IN BRAIN TUMORS}

Cancers are not simple collections of homogeneous neoplastic cells. Instead, a tumor is an organ system comprised of a neoplastic compartment with associated vasculature, inflammatory cells, and reactive cellular and extracellular components (Reya et al. 2001). Bailey and Cushing (1926) long ago recognized that brain cancers display striking morphologic variation, as evidenced by the term glioblastoma multiforme. Glial tumors often contain mixed subpopulations that morphologically resemble astrocytes and oligodendrocytes, leading to an intermediate diagnosis of oligoastrocytomas in the WHO classification system. Genetic analysis has additionally demonstrated that chromosomal aberrations and gene expression vary regionally within the tumor (Fulci et al. 2002). Regional variance is also evident in the commonly observed mixed clinical responses detected for specific therapies, in which part of the tumor may be responsive to a therapy, whereas other areas of the tumor fail to respond (Pope et al. 2006). Differentiation markers have been assessed in human brain tumors and demonstrate that aberrant and multiple states of differentiation may be present in the same tumor.

Our understanding of the normal development of the nervous system has dramatically increased in recent years. The nervous system has a complex differentiation hierarchy ranging from a neural stem cell that can give rise to all of the major lineages in the brain parenchyma (primarily neurons, astrocytes, and oligodendrocytes) to lineage-committed progenitors that have a more restricted 

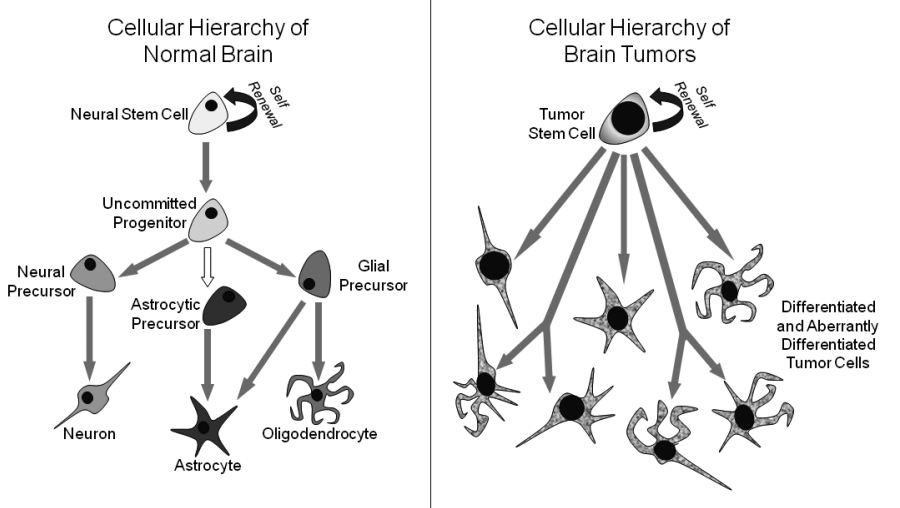

Figure 1. Brain tumors display a cellular hierarchy that resembles, but differs from, the normal neural cell hierarchy. Normal neural stem cells have the ability to self-renew while also dividing, to give rise to uncommitted progenitor cells that, in turn, give rise to lineage-restricted committed progenitors and finally to differentiated astrocytes, oligodendrocytes, and neurons. Similarly, tumors appear to have a cellular hierarchy, with self-renewing glioma stem cells able to generate a variety of more differentiated progeny, although patterns of differentiation appear to be less discrete than those in the normal brain. Many of the cancer stem cell-derived progeny display aberrant differentiation patterns, expressing more than one type of differentiation marker.

differentiation potential to terminally differentiated cells (Fig. 1) (Uchida et al. 2000; Rietze et al. 2001; Sanai et al. 2004). The recognition of the importance of differentiation state and the role of neural stem cells in development and wound responses (two processes that are recapitulated in carcinogenesis) have prompted the application of neural stem cell biology to neuro-oncology. Stem cell concepts can influence the understanding of brain cancer in two prominent areas: tumor origin and maintenance. The cell of origin for brain tumors is unresolved with genetic models supporting either a stem cell origin or a dedifferentiated committed cell of origin, with even more recent evidence suggesting a potential dual origin with a common final morphology (for review, see Furnari et al. 2007). No less controversial, the cancer stem cell hypothesis proposes that established tumors consist of a cellular hierarchy with a subpopulation of tumor cells able to maintain and propagate the tumor. Two competing models have been proposed: a stochastic model, in which any cell within the tumor has an equal chance of growth based on the genetic phenotype of the cell, and the hierarchical model, in which a subset of neoplastic cells can maintain tumor growth indefinitely (Reya et al. 2001). The initial identification of a cancer stem cell occurred in leukemia (Lapidot et al. 1994; Bonnet and Dick 1997), but similar identifications in multiple systemic cancer types have followed (Al-Hajj et al. 2003; Hope et al. 2004; Dalerba et al. 2007; Li et al. 2007; O'Brien et al. 2007; Ricci-Vitiani et al. 2007). Cancer stem cells displaying these properties have been isolated from major types of brain tumors including gliomas, medulloblastomas, and ependymomas (Fig. 2) (Ignatova et al. 2002; Hemmati et al. 2003; Singh et al. 2003, 2004; Galli et al. 2004; Yuan et al. 2004; Taylor et al. 2005). Several issues have contributed to controversies surrounding the cancer stem cell hypothesis. These include (1) evidence that some cancers or some tumor models do not display a recognizable hierarchy (Quintana et al. 2008), (2) lack of universal markers that identify cancer stem cells, and (3) confusion regarding the implications of the cancer stem cell hypothesis in terms of the rarity of cancer stem cells (Kelly et al. 2007) and implications regarding the cell of origin. The cancer stem cell hypothesis does not require a rare cancer stem cell nor a stem cell origin for tumors (Clarke et al. 2006). It is unlikely that stem cell biology will explain the entirety of brain tumor biology, but it is increasingly evident that

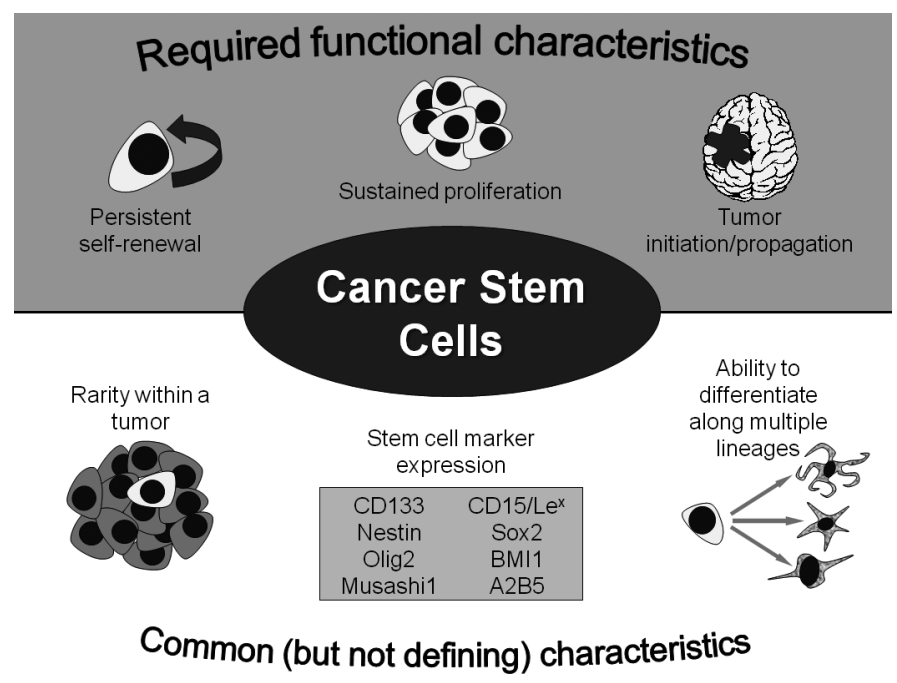

Figure 2. Cancer stem cells are defined by a capacity for sustained self-renewal, persistent proliferation, and tumor initiation or propagation. Some characteristics that are often, but not necessarily, associated with brain tumor stem cells include rarity within a tumor, expression of stem cell markers, and a capacity for multilineage differentiation. 
stem cell signal transduction pathways are commonly dysregulated in brain tumors and that a tumor population can be commonly derived from human brain tumor surgical specimens that exhibit characteristics similar to those of normal stem cells. The acceptance of a cancer stem cell model is not mutually exclusive with a stochastic model of tumor initiation and maintenance that has been the leading paradigm in cancer biology for years, but it appears probable that these systems may be used in complement to inform research.

\section{DEFINING BRAIN TUMOR STEM CELLS}

No current agreement exists regarding the definition of a normal stem cell beyond long-term renewal and differentiation potential, so it is of little surprise that there is limited consensus regarding the defining characteristics of cancer stem cells. The current definition of a cancer stem cell requires self-renewal, sustained proliferation, and tumor initiation/propagation (Clarke et al. 2006). Because the stem-cell-like populations are defined in functional assays, some investigators have selected a nomenclature to represent the ability of cells to propagate tumors, but these terms fail to communicate that core characteristics may be shared between these tumor cells and normal stem cells (markers, signal transduction pathways, self-renewal capacity, etc.).

Normal stem cells commonly express specific antigens that permit prospective enrichment of cells that fulfill stem cell criteria, but no antigenic profile (the immunophenotype) is absolutely representative of a stem cell. Thus, we lack the ability to directly assess the creation of a perfect copy of a cell in real time. Rather, stem cell assays validate that a cell capable of self-renewal must have been present during an earlier step. Stem cells have developmentally regulated replication that can be either symmetric (yielding two identical cells - either two stem cells or two differentiated daughter cells) or asymmetric (giving rise to one differentiated and one undifferentiated daughter cell) in response to cell state and external cues. Measuring the differentiation status of a cell in a single division presents significant challenges to score a division as symmetric or asymmetric. To date, current techniques have included measurement of polarized proteins including Notch (Wu et al. 2007), but current techniques cannot verify in real time that a daughter cell has not undergone differentiation. The gold standard for defining a normal adult stem cell remains the generation of the full cellular constituents of the relevant organ from a single stem cell. For the nervous system, the ability to form neurons, astrocytes, and oligodendrocytes is required of normal neural stem cells. The differentiation cascade for the hematopoietic system is by far the best characterized, but the nervous system is increasingly well modeled. In cell culture systems without serum, neural progenitors may form three-dimensional structures called neurospheres that do not adhere to the culture surface. These complex structures tend to have the least differentiated cellular populations located on the surface of the sphere, with expression of differentiation markers more commonly occurring on cells in the interior. Complex neuronal processes may be formed in these structures, and some correlation of similar structures in the breast (mammospheres) has permitted an assessment of self-renewal through the serial passage of the spheres from single cells and of proliferation rate from the size of the generated spheres. However, caution must be exercised in interpreting the significance of neurosphere generation (Singec et al. 2006). First, spheres may be generated from cells that were incompletely disaggregated with residual cohesive cells. Second, spheres may form and "grow" through the fusion of smaller structures that may be present at higher cellular densities. In addition, neurospheres are cell culture artifacts that do not have in vivo correlates. Finally, not all cells within a neurosphere have an undifferentiated state (in fact, stem-like cells are often a small minority) and even committed progenitors may be able to form a neurosphere. Thus, the presence of a neurosphere does not prove the presence of a stem cell in normal physiology.

Within the field of cancer stem cell biology, the current state of understanding has led to high variability in the rigor with which validation of the stem cell nature of a cellular population is approached. Many groups have simply used the presence of a stem cell marker or neurosphere generation as an indication of a cancer stem cell. This is inadequate, and these studies may create difficulty in a field that is already confusing and controversial. The requirements and challenges for the identification of a cancer stem cell are similar to those of normal stem cells. Two main approaches have been used to date. In the first, tumors are disaggregated and cultured in serum-free media until tumor spheres form (Ignatova et al. 2002; Hemmati et al. 2003; Galli et al. 2004; Yuan et al. 2004). These spheres are sequentially passaged to confirm sustained self-renewal. The advantage of this system is that it includes an important (if challenging) functional assay at the initial characterization. There are weaknesses, however, because the neurospheres are still mixed populations that represent only a small fraction of the original tumor. The underlying heterogeneity will, by definition, be lost. Although neurospheres can be subjected to differentiation conditions, it is unclear whether these conditions are fully representative of the diversity of cellular populations in the original tumor. In addition, serial neurosphere passage requires extended periods of cell culture that can rapidly (even in minutes) induce significant alterations in cellular biology and gene expression. Therefore, there has been a strong effort to identify cell surface antigens that can be used to prospectively enrich cancer stem cells from tumor populations immediately upon surgical resection (Singh et al. 2003, 2004). Although several markers may be informative in brain tumor stem cell identification (e.g., Prominin-1 [CD133], CD15 [SSEA1, Lewis x structure $\left(\mathrm{Le}^{\mathrm{x}}\right)$ ], A2B5, BMI1, Nestin, Sox2, and Musashi1), there are significant deficiencies with the current available markers. In our own studies, markers are only reliably useful in segregating tumor-initiation potential after immediate derivation from an in vivo environment, suggesting that marker expression in cancer stem cells requires interactions with the microenvironment. In summary, the current methods for enrichment for cancer stem cells remain imperfect and will require improvements. 
The gold standard for defining cancer stem cells remains tumor propagation. The current preferred assay is the in vivo limiting dilution assay, in which progressively smaller numbers of tumor cells are implanted in an orthotopic location to demonstrate the minimal number of cells required to form tumors (Singh et al. 2004). Presumably, the number of cells represents a surrogate for the frequency of true cancer stem cells. However, it is possible that for solid cancers, some tumors will require more than one cell to initiate tumor growth of even pure cancer stem cell populations. An ideal result would be to have single tumor cells demonstrate the capacity to form a tumor and give rise to daughter cells that share this characteristic (Quintana et al. 2008). To date, the brain tumor field has not seen reports of this efficiency but instead have a cellular requirement of 100-1000 from human surgical biopsy specimens (Singh et al. 2004; Bao et al. 2006a). Regardless, the requirement for in vivo tumor propagation is absolute. The many studies that solely assess tumor sphere formation or expression of a cancer stem cell marker cannot be considered to have demonstrated the presence of cancer stem cells and may detract from the field.

An unresolved question in the solid tumor cancer stem cell field revolves around the proliferative rate of cancer stem cells. Normal and leukemic stem cells share the ability to proliferate over the long term but are quiescent in normal conditions. In ex vivo studies, brain tumor stem cells are apparently proliferative, but this may represent a response to culture conditions. Preliminary studies of brain tumor specimens have suggested that tumors contain cells that coexpress cancer stem cell and proliferative markers, but the ability to distinguish a stem cell population from a transit-amplifying/committed progenitor population remains unreported.

The cancer stem cell hypothesis has engendered criticism due to a lack of clarity in the terminology. Many researchers and the lay public assume that a cancer stem cell is derived from a normal stem cell. Conceptually, brain tumors may be derived from neural stem cells, transit-amplifying cells, or terminally differentiated cells. A stem cell cell of origin is an attractive hypothesis because the long life of these cells would permit the accumulation of genetic and epigenetic alterations required for transformation. In addition, many characteristics of normal neural stem cells are similar to characteristics of cells in high-grade brain tumors (including diversity of cell populations, high migratory potential, and sustained proliferation). Several genetically engineered brain tumor models suggest that neural stem cells may be transformed with restricted oncogenic stimuli (for review, see Furnari et al. 2007). However, other models support a potential for dedifferentiation of more differentiated cells in tumor origination. Very recently, two groups in parallel have demonstrated that identical tumors (medulloblastomas) can be derived from different cells of origin with identical genetic alterations, strongly supporting a model in which cancers that display similar morphologies may be derived from different starting points (Schüller et al. 2008; Yang et al. 2008a). It is likely that no single rule may be applied to the originating cell for a single cancer.

\section{DERIVATION OF BRAIN TUMOR STEM CELLS}

Our approach in cancer stem cell derivation has been built on the seminal studies by the Dirks laboratory that were in turn based on protocols for neural stem cell derivation (Singh et al. 2003, 2004). We have used tumor sources of human surgical biopsy specimens immediately collected after resection and tumor xenografts maintained in an in vivo environment. We disaggregate these tumors and then prospectively sort for a single cell surface marker, Prominin-1 (cluster of differentiation 133 [CD133]), which is the most developed brain tumor stem cell marker. Prominin-1, a pentaspan transmembrane glycoprotein located on cellular protrusions, was originally identified separately through the development of antibodies against the mouse neuroepithelium (Weigmann et al. 1997) and CD34 ${ }^{\text {bright }}$ hematopoietic stem and progenitor cells derived from human fetal liver, bone marrow, and blood (Miraglia et al. 1997; Yin et al. 1997). The function of Prominin-1 is unknown, but mutations in Prominin-1 are detected in patients with familiar macular degeneration, and they disrupt photoreceptor disk morphogenesis in a genetic mouse model (Yang et al. 2008b).

CD133 was first used to enrich tumor-repopulating cells in leukemia (Bühring et al. 1999; Horn et al. 1999) and informed prognosis (Lee et al. 2001). On the basis of its expression on neural stem/progenitor cells, CD133 was investigated as a brain tumor stem cell marker. In seminal studies first performed in vitro and then in vivo, brain tumor stem cells were exclusively detected in $\mathrm{CD}_{133^{+}}$ cells from gliomas and medulloblastomas (Singh et al. 2003, 2004). Tumor-derived neurospheres from pediatric brain tumors also express CD133 and other stem cell markers (Sox2, Musashi-1, Bmi-1, maternal embryonic leucine zipper kinase, and phosphoserine phosphatase) (Hemmati et al. 2003). The CD133 marker is not absolute but has proven useful for segregating tumorigenic potential for the majority of tumors in our laboratory. The primary advantage to this approach is that the cellular heterogeneity that is the core of the cancer stem cell hypothesis is maintained. The cells that are collected are then cultured in appropriate media: Stem cell populations are grown in defined media with growth factors (Lee et al. 2006) but without serum, whereas non-stem-cell populations are maintained in serum. Under these conditions, cancer stem cells will tend to form neurosphere-like structures and nonstem cells will grow as adherent cells. We have found that the cells in both populations rapidly accumulate changes in gene expression and genetic markers when cultured, suggesting that characterization of cancer stem cells and their matched non-stem-cell brethren should be performed at low passage number. Even this caveat is likely inadequate because phosphorylated proteins become altered within minutes after culturing, but our current technologies do not permit a perfect system to maintain the original cellular phenotype. Even in the earliest reports using CD133, the investigators recognized variation among tumors in marker expression. CD133 is also informative in ependymomas in conjunction with other markers (Nestin and brain lipidbinding protetin [BLBP]) (Taylor et al. 2005). Many 
reports have confirmed the utility of CD133 in prospective isolation of brain tumor stem cells (Bao et al. 2006a, b, 2008; Piccirillo et al. 2006; Calabrese et al. 2007), and CD133 has proven useful in a number of other solid cancers, including colorectal cancers (O'Brien et al. 2007; Ricci-Vitiani et al. 2007). However, challenges to the universal expression of CD133 have arisen, and some tumors have tumor-propagating potential without significant numbers of $\mathrm{CD}_{133^{+}}$cells (Beier et al. 2007). Interestingly, primary glioblastomas have much higher levels of $\mathrm{CD} 133^{+}$ cells than do recurrent tumors. The difficulties with CD133 are multiple. For example, AC133 reagents (monoclonal antibodies against the CD133 glycoprotein) are challenging to use (Bidlingmaier et al. 2008). In flow cytometry assays, $\mathrm{CD} 133^{+}$peaks are not fully separated from isotype antibody control peaks in most tumor preparations. Without a clear separation, CD133- and $\mathrm{CD} 133^{+}$populations cannot be clearly delineated and require functional validation. The precise methodologies used to disaggregate tissues and purify cellular populations can have profound effects on CD133 fractions (Panchision et al. 2007). Cell culture conditions are important to maintain appropriate tumor stem cell populations (Lee et al. 2006), but direct transfer to an in vivo environment may be optimal for preservation of a CD133 ${ }^{+}$tumor cell fraction (Shu et al. 2008). CD133 is not a static gene product but is a target of promoter methylation alterations in cancers (Tabu et al. 2008; Yi et al. 2008) and may be regulated during the cell cycle (Jaksch et al. 2008). The complexity of these conditions has translated into the common use of very small numbers of tumor specimens in even high-impact reports. It is almost certainly the case, however, that morphologically identical brain tumors have underlying complex cellular differences due to different cell-of-origin or oncogenic changes that are represented with different brain tumor stem cells that may express different marker immunophenotypes.

\section{THE SIGNIFICANCE OF BRAIN TUMOR STEM CELLS IN NEURO-ONCOLOGY}

Although it may appear that the cancer stem cell hypothesis is merely an academic exercise or a laboratory phenomenon, one cannot deny the near total failure in the development of therapies to improve the outcomes of brain cancer patients using traditional laboratory-investigative approaches. The use of temozolomide has been hailed as a tremendous advance in the treatment of malignant gliomas, but the benefit has been limited to less than 3 months of improved median survival for glioblastoma patients (Stupp et al. 2005). Not only has the genetic knowledge of brain tumor biology been inadequate to drive new effective therapies, but advanced imaging technologies are still unreliable in early tumor detection and prediction of the most important outcome: survival. The heterogeneity of brain cancers may be helpful in explaining many of our failures. To date, no direct proof of a role for cancer stem cells in brain tumor clinical trials has been reported, but several studies have examined the expression of cancer stem cell marker-positive cells in clinical brain tumor biopsy specimens.
CD133 immunohistochemistry of brain tumor specimens has shown variability in utility, likely due to the combination of tumor heterogeneity and reagent specificity. $\mathrm{CD}_{133^{+}}$cells reside in a perivascular niche of tumors (Bao et al. 2006b; Calabrese et al. 2007; Christensen et al. 2008). Analysis of CD133 and proliferation has not demonstrated consistent relationships to date (Christensen et al. 2008; Ma et al. 2008), but CD133 may inform prognosis (Beier et al. 2008; Howard and Boockvar 2008; Thon et al. 2008; Zeppernick et al. 2008), although some studies have failed to demonstrate a link (Christensen et al. 2008). One study (Liu et al. 2006) found that CD133 mRNA increased after tumor recurrence. In summary, it is premature to consider CD133 to be a validated prognostic indicator. The validation of other potential markers remains less developed.

\section{BRAIN TUMOR STEM CELLS IN THERAPEUTIC RESISTANCE}

Unfortunately, patients afflicted with malignant gliomas suffer nearly universal treatment failure and death. As described above, surgical resection and cytotoxic modalities (radiation, chemotherapy) remain the mainstay of brain tumor therapy (of note, antiangiogenic therapy in the form of the humanized neutralizing antibody against vascular endothelial growth factor [VEGF] has shown initial promise). The mechanisms through which brain tumors become resistant to conventional therapy are poorly understood and are likely multifactorial. We examined a potential contribution of brain tumor stem cells to radiation resistance (Bao et al. 2006a). We found that ionizing radiation increased the relative frequency of tumor cells expressing cancer stem cell markers in treated xenografts. The relative enrichment of these cells was accompanied by maintained capacity for self-renewal and tumor propagation, whereas matched nonstem cancer cells were more likely to die. Cancer stem cell-enriched cultures treated with radiation demonstrate a lower apoptotic fraction than do nonstem cells in the same conditions, allowing for the outgrowth of cancer stem cells. To elucidate a potential mechanism, we studied the DNA-damage checkpoint response in which a cascade of proteins integrates signals from damage sensors to determine whether cells will initiate a cell cycle arrest with DNA repair or undergo apoptosis. Cancer stem cells treated with radiation or radio-mimetics displayed an increased activation of the DNA-damage checkpoint response compared to that of matched nonstem cancer cells. Although the activated proteins showed variability among samples, some proteins appeared to be activated at baseline (e.g., Rad17), as if the cancer stem cells were primed to respond to genotoxic stress, which may be an early event in cancer initiation. The role of the DNA-damage checkpoint response proved contributory because a pharmacologic inhibitor of the checkpoint sensitized the cancer stem cells to radiation. These results were supported by studies in genetically engineered medulloblastomas (Hambardzumyan et al. 2008). Other researchers have also found that neurosphere-forming brain tumor cells are more resistant to chemotherapy than are similar cells grown under differentiating conditions (Liu et al. 2006). In sum, although these 
studies suggest that cancer stem cells may contribute to the common therapeutic resistance of brain tumors and may be targetable with pharmacologic approaches, it also seems unlikely that the full extent of resistance in brain tumors derives from cancer stem cells.

\section{BRAIN TUMOR STEM CELLS IN ANGIOGENESIS}

Malignant gliomas are commonly angiogenic, with vascular proliferation serving as an informative histologic feature indicating a glioblastoma among the gliomas. Many growth factors are secreted by malignant gliomas to stimulate and maintain neoangiogenic vasculature. Targeted therapies have been developed against some of these pathways (for review, see Jain et al. 2007). Most clinical trials have demonstrated modest benefits from these agents, but a potential clinical efficacy has been seen in several trials of bevacizumab (Avastin), a neutralizing antibody against VEGF (Vredenburgh et al. 2007a,b). Interestingly, the activity of low-molecular-weight inhibitors against the VEGF receptors have been more modest in clinical trials, suggesting that the same molecular pathway may be targeted by different agents with different outcomes. During our studies of brain tumor stem cells, we noted that cancer stem cells form highly angiogenic tumors compared to the uncommon tumors that we detect in propagation studies with cancer stem cell-depleted cultures (Bao et al. 2006b). We found that conditioned media from cancer stem cells strongly induced endothelial cell migration, proliferation, and tube formation in contrast to nonstem cancer cell conditioned media. Characterization of angiogenic proteins in the conditioned media revealed a consistent up-regulation of VEGF. We were able to specifically block the effects of cancer stem cell conditioned media on endothelial cells using bevacizumab. In animal studies, bevacizumab strongly reduced the growth of tumors derived from cancer stem cells to a size and paucity of vascularity that is nearly identical to that of the uncommon tumors formed by nonstem cancer cells. Because nonstem cancer cells can survive implantation but rarely form tumors, the angiogenic drive may provide one explanation for the striking tumor propagation of cancer stem cells. In addition, cancer stem cells may provide an angiogenic drive to support the growth of nonstem cancer cells, suggesting that their effects in the tumor may not need to be limited solely to the direct production of progeny. In our studies, we noted that the cancer stem cells appeared to be located near the vasculature. These observations have been confirmed and extended in a seminal study that demonstrated that brain tumor stem cell growth is supported by endothelial cells and that tumor formation by the cancer stem cells requires support from a vascular niche (Calabrese et al. 2007). Additional studies further indicate the presence of cancer stem cell marker-positive cells located in the perivascular niche of patient specimens. In sum, these studies suggest that brain tumor stem cells have the ability to form their own tumor microenvironment through the elaboration of angiogenic factors, but at the same time, they remain dependent on that niche (Gilbertson and Rich 2007). These results may partially explain both the clinical activity of bevacizumab and the invasive phenotype in patients who suffer failure after bevacizumab treatment, because cancer stem cells display an invasive phenotype.

\section{TARGETING BRAIN TUMOR STEM CELLS}

There have been numerous recent reports of molecular targets that may be useful in ablating brain tumor stem cells. Several of these reports have focused on core stem cell/differentiation pathways, including BMI1 (Bruggeman et al. 2007; Godlewski et al. 2008), bone morphogenic protein (BMP) (Piccirillo et al. 2006), sonic hedgehog (Bar et al. 2007; Clement et al. 2007), Sox2 (Gangemi et al. 2008), Oct4 (Du et al. 2008), and Notch (Fan et al. 2006). Inhibitors of growth factor pathways, including epidermal growth factor (EGF) (Soeda et al. 2008) and plateletderived growth factor (PDGF), may be also be useful against brain tumor stem cells. To discover new molecular targets, we have compared expression of gene products or activated signal transduction pathways between cancer stem cells and nonstem cancer cells. The rationale behind this approach is that previously unrecognized targets may be discovered in the small fraction of cells that we have found to be cancer stem cells in brain tumors (it is again important to note that cancer stem cells may not necessarily be uncommon).

In one study, we found that the cell surface protein L1 cell adhesion molecule (L1CAM, CD171) is preferentially expressed in brain tumor stem cell-enriched cultures (Bao et al. 2008). L1CAM cosegregates with CD133 in glioblastoma patient biopsy specimens and is expressed at higher levels than in human neural progenitors. L1CAM contributes to brain tumor stem cell survival as targeting L1CAM expression through lentiviral short hairpin RNA (shRNA) specifically induced apoptosis in brain tumor stem cell cultures and ablated neurosphere formation. We found that L1CAM mediates its effects on brain tumor stem cells at least in part through the regulation of the transcriptional regulator Olig2. Other studies have demonstrated that the targeted disruption of Olig2 in genetically engineered brain tumor models blocks tumor initiation (Ligon et al. 2007). In our studies, targeting L1CAM decreased Olig2 expression and increased the expression of the key Olig2 target, the p21 $1^{\mathrm{CIP} 1 / \mathrm{WAF} 1}$ cyclin-dependent kinase inhibitor, and overexpression of Olig2 rescued the effects of L1CAM targeting. Most importantly, targeting L1CAM either before xenotransplantation or in established tumors reduced tumor growth and extended the life span of mice bearing tumor stem cell xenografts. These results demonstrated that analysis of brain tumor stem cells can identify novel molecular targets that may be useful for brain tumor therapy.

The phosphoinositol-3 kinase (PI3K) pathway is commonly dysregulated in malignant gliomas through mutations in either the subunits of PI3K or the phosphatase and tensin homolog (PTEN) tumor suppressor gene (Cancer Genome Atlas Research Network 2008). PI3K functions in part through regulation of the Akt/protein kinase B (PKB) survival pathway. We therefore examined the activation state of Akt in brain tumor stem cells compared to matched nonstem tumor cells (Eyler et al. 2008). The 
level of activating phosphorylation of Akt was lower at baseline in brain tumor stem cell cultures but was also more sensitive to inhibitory effects of low-molecularweight Akt inhibitors. Whereas Akt inhibition of nonstem tumor cells was largely cytostatic, tumor stem cells displayed an apoptotic response with Akt or PI3K inhibitors. Akt inhibitors also reduced neurosphere formation and invasion. Finally, tumor initiation was impaired by Akt inhibition. These results and those of other laboratories studying BMP, Notch, sonic hedgehog (SHH), and epidermal growth factor (EGFR) (Fan et al. 2006; Piccirillo et al. 2006; Bar et al. 2007; Clement et al. 2007; Lee et al. 2008; Soeda et al. 2008) suggest that brain tumor stem cells may be particularly sensitive to targeted therapies against signal transduction pathways.

The c-myc oncogene is commonly involved in cancer initiation and maintenance, but the role of c-myc in glioma biology is poorly understood. We examined the potential role of c-myc in brain tumor stem cells as a result of its involvement in normal stem cell biology (Wang et al. 2008). Glioma stem cells derived from human surgical biopsies consistently expressed higher levels of c-myc mRNA and protein relative to the nonstem tumor cells. Targeting c-myc expression was cytostatic in nonstem tumor cells but potently induced apoptosis and blocked self-renewal in the glioma stem cells. Most importantly, targeting c-myc expression completely blocked tumor propagation in transplantation studies. These results are very similar to those of a genetically engineered glioma model in which p53 and Pten are disrupted (Zheng et al. 2008).

These and several other studies have laid the foundation for novel insights into brain tumor biology through the analysis of molecular regulators of brain tumor stem cells. The extension of these studies into combination regimens with other therapies and potential clinical trial application may offer improved clinical outcomes.

\section{PERSPECTIVE}

Neuro-oncology has witnessed some important therapeutic advances, particularly in the treatment of pediatric brain tumors. Unfortunately, the outcome for adult patients with the most common intrinsic primary brain tumor, glioblastoma multiforme, continues to be extremely poor, with even the most exciting advances providing only minimal improvement in median survival in clinical trials. Fundamental changes in our paradigm in the development of prognostic markers, imaging, and therapy must occur for real change in patient outcome. It is potentially useful to take lessons from another area of medicine: infectious diseases. Mycobacterium tuberculosis (Mtb) is a major health burden in the developing world and in immunocompromised hosts. Few new effective antituberculosis agents have been developed. Recent studies suggest that traditional high-throughput Mtb drug development assays that essentially and nonspecifically target proliferation may not be useful for improving patient outcome because the model does not recapitulate in vivo conditions (Nathan et al. 2008). Rather, Mtb displays a cellular heterogeneity in a small fraction of the total population that is resistant to conventional therapies and is relatively quiescent. Nonreplicating bacte- ria may be critical to the problem of persistent Mtb infection. The striking parallels to cancer stem cell biology cannot be ignored and are not surprising because nature tends to repeat patterns. It is probable that not all cancers display a clear cellular hierarchy of tumor growth but the heterogeneity of cancers is essential to incorporate in models. The concept of stem-cell-like cells within brain tumors is not new, but recent technologies have improved the ability to prospectively enrich for cancer stem cells, and the recent increase in genetic understanding of brain tumors has informed the development of genetic brain tumor models. Although it is unlikely that brain tumor stem cells will inform all of brain tumor biology, our current failure in clinical neuro-oncology demands the aggressive investigation of new areas of research. Our studies and those of other laboratories have suggested that brain tumor stem cells contribute to therapeutic resistance, tumor angiogenesis, and invasion. Further characterization of this cellular fraction may guide the development of biomarkers, imaging modalities, and treatments that will hopefully be more effective. However, this field is immature and progress will likely be made with stumbles and errors and will be a learning process. The current challenge in deriving and maintaining brain tumor stem cells is a major limitation in the field because most laboratories do not have access to viable clinical specimens and animal resources. However, it is important to find ways to adapt these techniques for widespread use because there is currently insufficient evidence to show that established cell lines maintained for long periods in serum are useful in cancer stem cell studies. Cell cultureparticularly long-term cell culture in medium containing serum - is well recognized to induce genetic changes that were not present in the original tumor, limiting the utility of cell lines in modeling the original disease. The development of validated brain tumor models that can be shared in the field would be an important step forward. In addition, the functional assays for all brain tumor stem cell studies must be standardized with current use of serial neurosphere formation as a surrogate for self-renewal and tumor propagation. Available markers for brain tumor stem cells are imperfect and cannot be definitively linked to a stem cell phenotype, supporting an urgent need for improved markers. Because brain tumors are likely heterogeneous diseases, universal marker immunophenotypes may not be identifiable, but markers may assist in subcategorizing tumors. Molecular regulators of brain tumor stem cells may provide biomarkers, imaging targets, and therapeutic targets, but it is likely that molecules may be shared with normal somatic stem cells and thus their use may be complicated. Regardless of the outcome, the recognition of the potential importance of the cancer stem cell hypothesis has energized brain tumor research. The healthy debate between believers and skeptics will almost certainly lead to completely unforeseen directions in the field of brain tumor research and therapeutic development. In the end, we all hope to help those patients and families who are afflicted by brain tumors.

\section{ACKNOWLEDGMENTS}

Financial support was provided by the Childhood Brain Tumor Foundation, Pediatric Brain Tumor Foundation of 
the United States, Accelerate Brain Cancer Cure, Alexander and Margaret Stewart Trust, Brain Tumor Society, Goldhirsh Foundation, Duke Comprehensive Cancer Center Stem Cell Initiative Grant, and National Institutes of Health grants NS047409, NS054276, CA129958, and CA116659. J.R. is a Damon RunyonLilly Clinical Investigator supported by the Damon Runyon Cancer Research Foundation.

\section{REFERENCES}

Al-Hajj, M., Wicha, M.S., Benito-Hernandez, A., Morrison, S.J., and Clarke, M.F. 2003. Prospective identification of tumorigenic breast cancer cells. Proc. Natl. Acad. Sci. 100: 3983-3988.

Bailey, P. and Cushing, H.A. 1926. A classification of the gliomata. In Classification of the tumors of the glioma group on a histogenetic basis with a correlated study of prognosis, pp. 53-95. Lippincott, Philadelphia.

Bao, S., Wu, Q., Li, Z., Sathornsumetee, S., Wang, H., McLendon, R.E., Hjelmeland, A.B., and Rich, J.N. 2008. Targeting cancer stem cells through L1CAM suppresses glioma growth. Cancer Res. 68: 6043-6048.

Bao, S., Wu, Q., McLendon, R.E., Hao, Y., Shi, Q., Hjelmeland, A.B., Dewhirst, M.W., Bigner, D.D., and Rich J.N. 2006a. Glioma stem cells promote radioresistance by preferential activation of the DNA damage response. Nature 444: 756-760.

Bao, S., Wu, Q., Sathornsumetee, S., Hao, Y., Li, Z., Hjelmeland, A.B., Shi, Q., McLendon, R.E., Bigner, D.D., and Rich, J.N. 2006b. Stem cell-like glioma cells promote tumor angiogenesis through vascular endothelial growth factor. Cancer Res. 66: 7843-7848.

Bar, E.E., Chaudhry, A., Lin, A., Fan, X., Schreck, K., Matsui, W., Piccirillo, S., Vescovi, A.L., DiMeco, F., Olivi, A., and Eberhart, C.G. 2007. Cyclopamine-mediated Hedgehog pathway inhibition depletes stem-like cancer cells in glioblastoma. Stem Cells 25: 2524-2533.

Beier, D., Wischhusen, J., Dietmaier, W., Proescholdt, M., Brawanski, A., Bogdahn, U., and Beier, C.P. 2008. CD133 expression and cancer stem cells predict prognosis in highgrade oligodendroglial tumors. Brain Pathol. 18: 370-377.

Beier, D., Hau, P., Proescholdt, M., Lohmeier, A., Wischhusen, J., Oefner, P.J., Aigner, L., Brawanski, A., Bogdahn, U., and Beier, C.P. 2007. CD133 ${ }^{+}$and CD133- glioblastoma-derived cancer stem cells show differential growth characteristics and molecular profiles. Cancer Res. 67: 4010-4015.

Bidlingmaier, S., Zhu, X., and Liu, B. 2008. The utility and limitations of glycosylated human CD133 epitopes in defining cancer stem cells. J. Mol. Med. 86: 1025-1032.

Bonnet, D. and Dick, J.E. 1997. Human acute myeloid leukemia is organized as a hierarchy that originates from a primitive hematopoietic cell. Nat. Med. 3: 730-737.

Bruggeman, S.W., Hulsman, D., Tanger, E., Buckle, T., Blom, M., Zevenhoven, J., van Tellingen, O., and van Lohuizen, M. 2007. Bmil controls tumor development in an Ink4a/Arfindependent manner in a mouse model for glioma. Cancer Cell 12: 328-341.

Bühring, H.J., Seiffert, M., Marxer, A., Weiss, B., Faul, C., Kanz, L., and Brugger, W. 1999. AC133 antigen expression is not restricted to acute myeloid leukemia blasts but is also found on acute lymphoid leukemia blasts and on a subset of CD34 ${ }^{+}$B-cell precursors. Blood 94: 832-833.

Calabrese, C., Poppleton, H., Kocak, M., Hogg, T.L., Fuller, C., Hamner, B., Oh, E.Y., Gaber, M.W., Finklestein, D., Allen, M., et al. 2007. A perivascular niche for brain tumor stem cells. Cancer Cell 11: 69-82.

Cancer Genome Atlas Research Network. 2008. Comprehensive genomic characterization defines human glioblastoma genes and core pathways. Nature 455: 1061-1068.

Christensen, K., Schrøder, H.D., and Kristensen, B.W. 2008. CD133 identifies perivascular niches in grade II-IV astrocytomas. J. Neurooncol. 90: 157-170.
Clarke, M.F., Dick, J.E., Dirks, P.B., Eaves, C.J., Jamieson, C.H., Jones, D.L., Visvader, J., Weissman, I.L., and Wahl, G.M. 2006. Cancer stem cells-Perspectives on current status and future directions: AACR Workshop on cancer stem cells. Cancer Res. 66: 9339-9344.

Clement, V., Sanchez, P., de Tribolet, N., Radovanovic, I., and Ruiz i Altaba, A. 2007. HEDGEHOG-GLI1 signaling regulates human glioma growth, cancer stem cell self-renewal, and tumorigenicity. Curr. Biol. 17: 165-172.

Dalerba, P., Dylla, S.J., Park, I.K., Liu, R., Wang, X., Cho, R.W., Hoey, T., Gurney, A., Huang, E.H., Simeone, D.M., et al. 2007. Phenotypic characterization of human colorectal cancer stem cells. Proc. Natl. Acad. Sci. 104: 10158-10163.

Du, Z., Jia, D., Liu, S., Wang, F., Li, G., Zhang, Y., Cao, X., Ling, E.A., and Hao, A. 2008. Oct4 is expressed in human gliomas and promotes colony formation in glioma cells. Glia (in press).

Eyler, C.E., Foo, W.C., Lafiura, K.M., McLendon, R.E., Hjelmeland, A.B., and Rich J.N. 2008. Brain cancer stem cells display preferential sensitivity to Akt inhibition. Stem Cells 26: 3027-3036.

Fan, X., Matsui, W., Khaki, L., Stearns, D., Chun, J., Li, Y.M., and Eberhart, C.G. 2006. Notch pathway inhibition depletes stem-like cells and blocks engraftment in embryonal brain tumors. Cancer Res. 66: 7445-7452.

Fulci, G., Ishii, N., Maurici, D., Gernert, K., Hainaut, P., Kaur, B., and Van Meir, E.G. 2002. Initiation of human astrocytoma by clonal evolution of cells with progressive loss of p53 functions in a patient with a $283 \mathrm{H}$ TP53 germline mutation: Evidence for a precursor lesion. Cancer Res. 62: 2897-2906.

Furnari, F.B., Fenton, T., Bachoo, R.M., Mukasa, A., Stommel, J.M., Stegh, A., Hahn, W.C., Ligon, K.L., Louis, D.N., Brennan, C., et al. 2007. Malignant astrocytic glioma: Genetics, biology, and paths to treatment. Genes Dev. 21: 2683-2710.

Galli, R., Binda, E., Orfanelli, U., Cipelletti, B., Gritti, A., De Vitis, S., Fiocco, R., Foroni, C., Dimeco, F., and Vescovi, A. 2004. Isolation and characterization of tumorigenic, stem-like neural precursors from human glioblastoma. Cancer Res. 64: 7011-7021.

Gangemi, R.M., Griffero, F., Marubbi, D., Perera, M., Capra, M.C., Malatesta, P., Ravetti, G.L., Zona, G.L., Daga, A., and Corte, G. 2009. SOX2 silencing in glioblastoma tumor initiating cells causes stop of proliferation and loss of tumorigenicity. Stem Cells 27: 40-48.

Gilbertson, R.J. and Rich, J.N. 2007. Making a tumour's bed: Glioblastoma stem cells and the vascular niche. Nat. Rev. Cancer 10: 733-736.

Godlewski, J., Nowicki, M.O., Bronisz, A., Williams, S., Otsuki, A., Nuovo, G., Raychaudhury, A., Newton, H.B., Chiocca, E.A., and Lawler, S. 2008. Targeting of the Bmi-1 oncogene/stem cell renewal factor by microRNA-128 inhibits glioma proliferation and self-renewal. Cancer Res. 22: 9125-9130.

Hambardzumyan, D., Becher, O.J., Rosenblum, M.K., Pandolfi, P.P., Manova-Todorova, K., and Holland, E.C. 2008. PI3K pathway regulates survival of cancer stem cells residing in the perivascular niche following radiation in medulloblastoma in vivo. Genes Dev. 22: 436-448.

Hemmati, H.D., Nakano, I., Lazareff, J.A., Masterman-Smith, M., Geschwind, D.H., Bronner-Fraser, M., and Kornblum, H.I. 2003. Cancerous stem cells can arise from pediatric brain tumors. Proc. Natl. Acad. Sci. 100: 15178-15183.

Hope, K.J., Jin, L., and Dick, J.E. 2004. Acute myeloid leukemia originates from a hierarchy of leukemic stem cell classes that differ in self-renewal capacity. Nat. Immunol. 5: 738-743.

Horn, P.A., Tesch, H., Staib, P., Kube, D., Diehl, V., and Voliotis, D. 1999. Expression of AC133, a novel hematopoietic precursor antigen, on acute myeloid leukemia cells. Blood 93: 1435-1437.

Howard, B.M. and Boockvar, J.A. 2008. Stem cell marker CD133 expression predicts outcome in glioma patients. Neurosurgery 62: N8.

Ignatova, T.N., Kukekov, V.G., Laywell, E.D., Suslov, O.N., Vrionis, F.D., and Steindler, D.A. 2002. Human cortical glial 
tumors contain neural stem-like cells expressing astroglial and neuronal markers in vitro. Glia 39: 193-206.

Jain, R.K., di Tomaso, E., Duda, D.G., Loeffler, J.S., Sorensen, A.G., and Batchelor, T.T. 2007. Angiogenesis in brain tumours. Nat. Rev. Neurosci. 8: 610-622.

Jaksch, M., Múnera, J., Bajpai, R., Terskikh, A., and Oshima, R.G. 2008. Cell cycle-dependent variation of a CD133 epitope in human embryonic stem cell, colon cancer, and melanoma cell lines. Cancer Res. 68: 7882-7886.

Kelly, P.N., Dakic, A., Adams, J.M., Nutt, S.L., and Strasser, A. 2007. Tumor growth need not be driven by rare cancer stem cells. Science 317: 337.

Lapidot, T., Sirard, C., Vormoor, J., Murdoch, B., Hoang, T., Caceres-Cortes, J., Minden, M., Paterson, B., Caligiuri, M.A., and Dick, J.E. 1994. A cell initiating human acute myeloid leukaemia after transplantation into SCID mice. Nature $\mathbf{3 6 7}$ : 645-648.

Lee, J., Kotliarova, S., Kotliarov, Y., Li, A., Su, Q., Donin, N.M., Pastorino, S., Purow, B.W., Christopher, N., Zhang, W., Park, J.K., and Fine, H.A. 2006. Tumor stem cells derived from glioblastomas cultured in bFGF and EGF more closely mirror the phenotype and genotype of primary tumors than do serum-cultured cell lines. Cancer Cell 9: 391-403.

Lee, J., Son, M.J., Woolard, K., Donin, N.M., Li, A., Cheng, C.H., Kotliarova, S., Kotliarov, Y., Walling, J., Ahn, S., et al. 2008. Epigenetic-mediated dysfunction of the bone morphogenetic protein pathway inhibits differentiation of glioblastoma-initiating cells. Cancer Cell 13: 69-80.

Lee, S.T., Jang, J.H., Min, Y.H., Hahn, J.S., and Ko, Y.W. 2001. AC133 antigen as a prognostic factor in acute leukemia. Leuk. Res. 25: 757-767.

Li, C., Heidt, D.G., Dalerba, P., Burant, C.F., Zhang, L., Adsay, V., Wicha, M., Clarke, M.F., and Simeone, D.M. 2007. Identification of pancreatic cancer stem cells. Cancer Res. 67: 1030 1037.

Ligon, K.L., Huillard, E., Mehta, S., Kesari, S., Liu, H., Alberta, J.A., Bachoo, R.M., Kane, M., Louis, D.N., Depinho, R.A., et al. 2007. Olig2-regulated lineage-restricted pathway controls replication competence in neural stem cells and malignant glioma. Neuron 53: 503-517.

Liu, G., Yuan, X., Zeng, Z., Tunici, P., Ng, H., Abdulkadir, I.R., Lu, L., Irvin, D., Black, K.L., and Yu, J.S. 2006. Analysis of gene expression and chemoresistance of CD133 ${ }^{+}$cancer stem cells in glioblastoma. Mol. Cancer 5: 67.

Ma, Y.H., Mentlein, R., Knerlich, F., Kruse, M.L., Mehdorn, H.M., and Held-Feindt, J. 2008. Expression of stem cell markers in human astrocytomas of different WHO grades. $J$. Neurooncol. 86: 31-45.

Miraglia, S., Godfrey, W., Yin, A.H., Atkins, K., Warnke, R., Holden, J.T., Bray, R.A., Waller, E.K., and Buck, D.W. 1997. A novel five-transmembrane hematopoietic stem cell antigen: Isolation, characterization, and molecular cloning. Blood 90: 5013-5021

Nathan, C., Gold, B., Lin, G., Stegman, M., de Carvalho, L.P., Vandal, O., Venugopal, A., and Bryk, R 2008. A philosophy of anti-infectives as a guide in the search for new drugs for tuberculosis. Tuberculosis (suppl. 1) 88: S25-S33.

O'Brien, C.A., Pollett, A., Gallinger, S., and Dick, J.E. 2007. A human colon cancer cell capable of initiating tumour growth in immunodeficient mice. Nature 445: 106-110.

Panchision, D.M., Chen, H.L., Pistollato, F., Papini, D., Ni, H.T., and Hawley, T.S. 2007. Optimized flow cytometric analysis of central nervous system tissue reveals novel functional relationships among cells expressing CD133, CD15, and CD24. Stem Cells 25: 1560-1570.

Piccirillo, S.G., Reynolds, B.A., Zanetti, N., Lamorte, G., Binda, E., Broggi, G., Brem, H., Olivi, A., Dimeco, F., and Vescovi, A.L. 2006. Bone morphogenetic proteins inhibit the tumorigenic potential of human brain tumour-initiating cells. Nature 444: 761-765.

Pope, W.B., Lai, A., Nghiemphu, P., Mischel, P., and Cloughesy, T.F. 2006. MRI in patients with high-grade gliomas treated with bevacizumab and chemotherapy. Neurology 8: 1258-1260.

Quintana, E., Shackleton, M., Sabel, M.S., Fullen, D.R., Johnson,
T.M., and Morrison, S.J. 2008. Efficient tumour formation by single human melanoma cells. Nature 456: 593-598.

Reya, T., Morrison, S.J., Clarke, M.F., and Weissman, I.L. 2001. Stem cells, cancer, and cancer stem cells. Nature 414: 105111.

Ricci-Vitiani, L., Lombardi, D.G., Pilozzi, E., Biffoni, M., Todaro, M., Peschle, C., and De Maria, R. 2007. Identification and expansion of human colon-cancer initiating cells. Nature 445: 111-115.

Rietze, R.L., Valcanis, H., Brooker, G.F., Thomas, T., Voss, A.K., and Bartlett, P.F. 2001. Purification of a pluripotent neural stem cell from the adult mouse brain. Nature 412: 736-739.

Sanai, N., Tramontin, A.D., Quiñones-Hinojosa, A., Barbaro, N.M., Gupta, N., Kunwar, S., Lawton, M.T., McDermott, M.W., Parsa, A.T., Manuel-García Verdugo, J., Berger, M.S., and Alvarez-Buylla, A. 2004. Unique astrocyte ribbon in adult human brain contains neural stem cells but lacks chain migration. Nature 427: 740-744.

Schüller, U., Heine, V.M., Mao, J., Kho, A.T., Dillon, A.K., Han, Y.G., Huillard, E., Sun, T., Ligon, A.H., Qian, Y., et al. 2008. Acquisition of granule neuron precursor identity is a critical determinant of progenitor cell competence to form Shh-induced medulloblastoma. Cancer Cell 2: 123-134.

Shu, Q., Wong, K.K., Su, J.M., Adesina, A.M., Yu, L.T., Tsang, Y.T., Antalffy, B.C., Baxter, P., Perlaky, L., Yang, J., et al. 2008. Direct orthotopic transplantation of fresh surgical specimen preserves $\mathrm{CD}_{133^{+}}$tumor cells in clinically relevant mouse models of medulloblastoma and glioma. Stem Cells 26: $1414-1424$.

Singec, I., Knoth, R., Meyer, R.P., Maciaczyk, J., Volk, B., Nikkhah, G., Frotscher, M., and Snyder, E.Y. 2006. Defining the actual sensitivity and specificity of the neurosphere assay in stem cell biology. Nat. Methods 3: 801-806.

Singh, S.K., Clarke, I.D., Terasaki, M., Bonn, V.E., Hawkins, C., Squire, J., and Dirks, P.B. 2003. Identification of a cancer stem cell in human brain tumors. Cancer Res. 63: 5821-5828.

Singh, S.K., Hawkins, C., Clarke, I.D., Squire, J.A., Bayani, J., Hide, T., Henkelman, R.M., Cusimano, M.D., and Dirks, P.B. 2004. Identification of human brain tumour initiating cells. Nature 432: 396-401.

Soeda, A., Inagaki, A., Oka, N., Ikegame, Y., Aoki, H., Yoshimura, S., Nakashima, S., Kunisada, T., and Iwama, T. 2008. Epidermal growth factor plays a crucial role in mitogenic regulation of human brain tumor stem cells. J. Biol. Chem. 283: 10958-10966.

Stupp, R., Mason, W.P., van den Bent, M.J., Weller, M., Fisher, B., Taphoorn, M.J., Belanger, K., Brandes, A.A., Marosi, C., Bogdahn, U., et al. 2005. Radiotherapy plus concomitant and adjuvant temozolomide for glioblastoma. N. Engl. J. Med. 352: 987-996.

Tabu, K., Sasai, K., Kimura, T., Wang, L., Aoyanagi, E., Kohsaka, S., Tanino, M., Nishihara, H., and Tanaka, S. 2008. Promoter hypomethylation regulates CD133 expression in human gliomas. Cell Res. 18: 1037-1046.

Taylor, M.D., Poppleton, H., Fuller, C., Su, X., Liu, Y., Jensen, P., Magdaleno, S., Dalton, J., Calabrese, C., Board, J., et al. 2005. Radial glia cells are candidate stem cells of ependymoma. Cancer Cell 8: 323-335.

Thon, N., Damianoff, K., Hegermann, J., Grau, S., Krebs, B., Schnell, O., Tonn, J.C., and Goldbrunner, R. 2008. Presence of pluripotent CD $133^{+}$cells correlates with malignancy of gliomas. Mol. Cell. Neurosci. (in press).

Uchida, N., Buck, D.W., He, D., Reitsma, M.J., Masek, M., Phan, T.V., Tsukamoto, A.S., Gage, F.H., and Weissman, I.L. 2000. Direct isolation of human central nervous system stem cells. Proc. Natl. Acad. Sci. 97: 14720-14725.

Vredenburgh, J.J., Desjardins, A., Herndon II, J.E., Dowell, J.M., Reardon, D.A., Quinn, J.A., Rich, J.N., Sathornsumetee, S., Gururangan, S., Wagner, M., et al. 2007a. Phase II trial of bevacizumab and irinotecan in recurrent malignant glioma. Clin. Cancer Res. 13: 1253-1259.

Vredenburgh, J.J., Desjardins, A., Herndon II, J.E., Marcello, J., Reardon, D.A., Quinn, J.A., Rich, J.N., Sathornsumetee, S., 
Gururangan, S., Sampson, J., et al. 2007b. Bevacizumab plus irinotecan in recurrent glioblastoma multiforme. J. Clin. Oncol. 25: 4722-4729.

Wang, J., Wang, H., Li, Z., Wu, Q., Lathia, J.D., McLendon, R.E., Hjelmeland, A.B., and Rich, J.N. 2008. c-Myc is required for maintenance of glioma cancer stem cells. PLoS One 11: e3769.

Weigmann, A., Corbeil, D., Hellwig, A., and Huttner, W.B. 1997. Prominin, a novel microvilli-specific polytopic membrane protein of the apical surface of epithelial cells, is targeted to plasmalemmal protrusions of non-epithelial cells. Proc. Natl. Acad. Sci. 94: 12425-12430.

Wu, M., Kwon, H.Y., Rattis, F., Blum, J., Zhao, C., Ashkenazi, R., Jackson, T.L., Gaiano, N., Oliver, T., and Reya, T. 2007. Imaging hematopoietic precursor division in real time. Cell Stem Cell 5: 541-554.

Yang, Z., Chen, Y., Lillo, C., Chien, J., Yu, Z., Michaelides, M., Klein, M., Howes, K.A., Li, Y., Kaminoh, Y., et al. 2008a. Mutant prominin 1 found in patients with macular degeneration disrupts photoreceptor disk morphogenesis in mice. $J$. Clin. Invest. 118: 2908-2916.

Yang, Z.J., Ellis, T., Markant, S.L., Read, T.A., Kessler, J.D., Bourboulas, M., Schüller, U., Machold, R., Fishell, G., Rowitch, D.H., Wainwright, B.J., and Wechsler-Reya, R.J. 2008b. Medulloblastoma can be initiated by deletion of Patched in lineage-restricted progenitors or stem cells. Cancer Cell 2: 135-145.

Yi, J.M., Tsai, H.C., Glöckner, S.C., Lin, S., Ohm, J.E., Easwaran, H., James, C.D., Costello, J.F., Riggins, G., Eberhart, C.G., et al. 2008. Abnormal DNA methylation of CD133 in colorectal and glioblastoma tumors. Cancer Res. 68: 8094-8103.

Yin, A.H., Miraglia, S., Zanjani, E.D., Almeida-Porada, G., Ogawa, M., Leary, A.G., Olweus, J., Kearney, J., and Buck, D.W. 1997. AC133, a novel marker for human hematopoietic stem and progenitor cells. Blood 90: 5002-5012.

Yuan, X., Curtin, J., Xiong, Y., Liu, G., Waschsmann-Hogiu, S., Farkas, D.L., Black, K.L., and Yu, J.S. 2004. Isolation of cancer stem cells from adult glioblastoma multiforme. Oncogene 23: 9392-9400.

Zeppernick, F., Ahmadi, R., Campos, B., Dictus, C., Helmke, B.M., Becker, N., Lichter, P., Unterberg, A., Radlwimmer, B., and Herold-Mende, C.C. 2008. Stem cell marker CD133 affects clinical outcome in glioma patients. Clin. Cancer Res. 14: 123-129.

Zheng, H., Ying, H., Yan, H., Kimmelman, A.C., Hiller, D.J., Chen, A.J., Perry, S.R., Tonon, G., Chu, G.C., Ding, Z., et al. 2008. p53 and Pten control neural and glioma stem/progenitor cell renewal and differentiation. Nature 7216: 1129-1133. 


\title{
$\$_{\mathrm{CSH}}^{\infty} \&$ Cold Spring Harbor Symposia SYMPOSIA on Quantitative Biology
}

\section{Cancer Stem Cells in Brain Tumor Biology}

\author{
J.N. Rich and C.E. Eyler
}

Cold Spring Harb Symp Quant Biol 2008 73: 411-420 originally published online March 27, 2009 Access the most recent version at doi:10.1101/sqb.2008.73.060

References This article cites 75 articles, 27 of which can be accessed free at: http://symposium.cshlp.org/content/73/411.full.html\#ref-list-1

License

Email Alerting Receive free email alerts when new articles cite this article - sign up in the box at the Service top right corner of the article or click here.

To subscribe to Cold Spring Harbor Symposia on Quantitative Biology go to: http://symposium.cshlp.org/subscriptions 